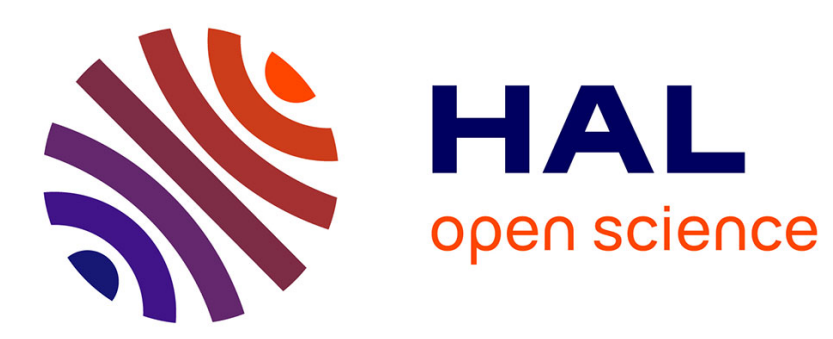

\title{
Public health intervention for narghile (hookah, shisha) use requires a radical critique of the related "standardised" smoking machine
}

Kamal Chaouachi

\section{- To cite this version:}

Kamal Chaouachi. Public health intervention for narghile (hookah, shisha) use requires a radical critique of the related "standardised" smoking machine. Journal of Public Health, 2009, 18 (1), pp.6973. 10.1007/s10389-009-0272-7. hal-00535284

\author{
HAL Id: hal-00535284 \\ https://hal.science/hal-00535284
}

Submitted on 11 Nov 2010

HAL is a multi-disciplinary open access archive for the deposit and dissemination of scientific research documents, whether they are published or not. The documents may come from teaching and research institutions in France or abroad, or from public or private research centers.
L'archive ouverte pluridisciplinaire HAL, est destinée au dépôt et à la diffusion de documents scientifiques de niveau recherche, publiés ou non, émanant des établissements d'enseignement et de recherche français ou étrangers, des laboratoires publics ou privés. 


\title{
Public health intervention for narghile (hookah, shisha) use requires a radical critique of the related "standardised" smoking machine
}

\author{
Kamal Chaouachi
}

Received: 19 January 2009 / Accepted: 2 June 2009/Published online: 23 July 2009

(C) Springer-Verlag 2009

\begin{abstract}
Aim Much has been written about the toxicity of narghile (hookah, shisha) smoke. However, it is seldom mentioned that narghile smoke is actually far less complex than that of cigarettes. In spite of being a much simpler object to research, there has been a world of avoidable and preventable confusion due, to a great extent, to the inappropriate use of the narghile smoking machine designed at the US-American University of Beirut that now is considered to be "standardised". This machine has allowed the claims of high yields of tar, $\mathrm{CO}, \mathrm{PAH}$, heavy metals and, lastly, volatile aldehydes. Consequently, any public health intervention against narghile (hookah, shisha) use requires a long overdue critique of this machine on which a large amount of the peer-reviewed "waterpipe" literature uncritically relies. Public health policy makers should be aware of the unprecedented degree of confusion in this field.

Methods The analysis is twofold. On one hand, the classical FTC (Federal Trade Commission) regime applied to cigarette testing (and behind the official figures printed on cigarette packs) is presented, whereby it is recalled that a $35-\mathrm{ml}$ puff is drawn each minute for only a few minutes. On the other hand, a discussion follows about the relevancy of the narghile smoking machine based on averaging a complex human and social activity to a puff relentlessly drawn every $17 \mathrm{~s}$ over a full hour, with, marginally, the heating source (coal) in the same position over the smoking mixture (contrary to common practice). It is assumed that such stress-strain conditions result in abnormal perturba-
\end{abstract}

K. Chaouachi $(\bowtie)$

DIU Tabacologie, Paris XI University,

18, allée des petits bois,

78000 Versailles, France

e-mail:kamcha@gmail.com tions in the chemical reactions at stake. The case of aldehyde generation is taken as an example.

Results The narghile smoking machine was modelled after the one for cigarettes, which not only is an inappropriate reference, but also is totally irrelevant for a kind of tobacco use that is different from all points of view. The narghile smoking machine and its underlying smoking topography represent a biased toxicological model of the related practice. Human-centered alternatives are presented.

Conclusion Against the background of a public health epidemic, a recommended research avenue is to focus on biological measurements of human subjects (urinary carcinogens, chemical or biological markers) carried out in a natural environment in realistic conditions and coupled with a puff-by-puff smoke analysis.

Keywords Smoking · Tobacco $\cdot$ Narghile $\cdot$ Shisha .

Smoking machine Puffing behaviour

\section{Introduction}

Much has been written about the toxicity of narghile (hookah, shisha) smoke. However, it is seldom mentioned that narghile smoke is actually far less complex than that of cigarettes. First in 1991, 142 compounds were detected in narghile smoke (El-Aasar and El-Merzabani 1991a). By comparison, 4,700 substances have been identified so far in cigarette smoke (Borgerding and Klus 2005). In spite of being a much simpler object to research, there has been a world of avoidable and preventable confusion due, to a great extent, to the inappropriate use of the narghile smoking machine designed at the US-American University of Beirut (US-AUB) that now is considered to be "standardised" (Al-Rashidi et al. 2008). For instance, a recent 
paper-reporting an absolutely unrealistic and extreme experiment about the 4-h exposure of three volunteers to the hazards of narghile smoke in an unventilated small room [which also raises serious ethical concerns (Helsinki Declaration 2008)]_relies heavily, in its discussion, on a comparison with yields obtained thanks to the abovementioned machine (Fromme et al. 2009). This experiment focussed on narghile ETS (environmental tobacco smoke) and charcoal emissions. However, unlike cigarettes, a narghile is known to generate almost no side-stream smoke so that its "second-hand smoke" has very often been hyped in an unscientific way (Chaouachi 2009). In two previous experimental studies on narghile smoke particles, Becquemin et al. (2008) and Monn et al. (2007) concluded, further to comparisons with the same US-AUB smoking machine, that there was a "Middle-Eastern" way of smoking vs. a "Western" one. Of course, this is a serious anthropometrical misrepresentation (Chaouachi 2009). Consequently, any public health intervention concerning narghile (hookah, shisha) use requires a long overdue critique of this smoking machine, which is too often referred to by policy makers advised by anti-smoking researchers and organisations.

\section{Discussion}

Usefulness of smoking machines Such tools can be useful, particularly in the first stage of a research work, as they can provide a first picture of the researched object, the same way astronautical engineers send robots to a remote planet for testing the ground and the surrounding space beforehand. At this stage, direct and quick conclusions are never drawn from the available raw data. Smoking machines can therefore be applied usefully for the calculation of ratios [nicotine to TSNAs (tobacco-specific nitrosamines), PAHs (polycyclic aromatic hydrocarbons), CO, etc.]. However, experts in this field have found that, as far as cigarettes are concerned, the existing smoking machines also have created a great deal of confusion because of the complex variability of human behaviour involving, among other things, compensation (i.e., body regulation of nicotine intake, etc.). Even the WHO (World Health Organisation) has issued recommendations in this respect (Hammond et al. 2007; Zielinski 2005; Chaouachi 2006).

Existing smoking machines Certain limits have unfortunately been transcended by the narghile smoking machine operated at the US-AUB (Al-Rashidi et al. 2008; Shihadeh and Saleh 2005). Certainly, toxicant yields of different brands of cigarettes can be compared. However, the first methodological bias is to compare yields of toxic substances (tar, nicotine, $\mathrm{CO}$, aldehydes, etc.) obtained under two completely different systems: on one hand, the FTC (Federal
Trade Commission) regime (one puff of $35 \mathrm{ml}$ every minute for a few minutes) designed for cigarettes and, on the other, the US-AUB's own regime (one puff of $530 \mathrm{ml}$ every $17 \mathrm{~s}$ for about 1 full hour) (Chaouachi 2007). The facts that, unlike cigarettes, glycerol and water form a large part of narghile's total particulate matter and that the temperatures differ by hundreds of degrees are other arguments for refraining from quick comparisons between cigarettes and narghile.

What is criticised here is neither the question of the averaged duration of the smoke puff $(2.6 \mathrm{~s})$ nor the fact that the heating source (coal) is kept at the same position above the bowl (containing the smoking mixture at the top of the pipe) for 1 full $\mathrm{h}$ (contrary to common practice in a natural human environment), nor even the puff volume. Concerning the latter, $300 \mathrm{ml}$ was not such an unrealistic approximation when compared with volumes involving the traditional plain tobacco used for centuries (tumbak). For instance, one of the first narghile smoking machines was based on a puff volume of $200 \mathrm{ml}$ for a bowl packed with tumbak (Rakower and Fatal 1962). However, since the fashionable smoking product used these days is more and more moassel/tobamel (a flavoured tobacco-molasses based mixture) and given that its mild smoke is inhaled (when it is) directly into the lungs with no previous stocking in the mouth, in striking contrast to cigarette smoking, an average smoke volume of $530 \mathrm{ml}$ may be acceptable.

Critique of the puff frequency (inter-puff smoulder time) What is actually criticised here relates to two importnat average parameters: the puffing frequency or, to be more precise, the inter-puff smoulder period, and, least important, the total number of puffs. The main reason is that the parameters selected for the US-AUB so-called "standardised" smoking machine do not take into account the many disruptions occurring during a 1-h smoking session. Indeed, a narghile smoker constantly expeiences all sorts of interruptions. People do not smoke a narghile like robots. Their behaviour depends to a great extent on the nature of the social situations in which they are involved. Amazingly, such contingent conditions and anthropological considerations that are of utmost importance have never been taken into account so far. They are not reflected at all in the smoking topography supposed to support the relevancy of the US-AUB smoking machine as a narghile model. Indeed, the corresponding graphs and tables of the underlying smoking topography show smokers puffing and dragging all the time. No micro, macro or "breath-taking" event is taken into account: conversation, reading, watching television, eating, drinking, sharing the hose, other interruptions such as changing of the coal by the café employee (Narghiljy) every 10 or $15 \mathrm{~min}$, etc. Furthermore, extrapolating this behaviour (modelled for only the first $30 \mathrm{~min}$ of a session) to the following $30 \mathrm{~min}$ was never demonstrated 
(Chaouachi 2007). Since such contingencies are already true among cigarette smokers whose puffs and puff duration, as well as the butt length, also vary according to their emotional state (Philip Morris 1967), it can be assumed that they are even more relevant to the study of narghile users who are known to dedicate much more time to their social "activity".

For instance, in view of the few minutes a cigarette needs to be consumed, an interruption like drinking coffee is necessarily sleeked by assuming - with no great error risk-that such an activity occurs between two cigarettes. However, this cannot be dismissed so easily when modelling a 60-min narghile smoking session together with many other details. Early deep healthoriented anthropological research showed that narghile smokers' activity over a full hour or more is not limited to puffing (Chaouachi 2007). Indeed, where would one place a cup of coffee during a so-called realistic smoking session when a puff is drawn every $17 \mathrm{~s}$ for a full hour? Interestingly, the so-called "intense" cigarette machinesmoking regime (the Massachussets one) is based on an inter-puff smoulder time of $30 \mathrm{~s}$ (puff of $45-\mathrm{ml}$ volume and 2-s duration) (Baker 2006a). Similarly, the 55-ml puff of the so-called Canadian "maximum" cigarette smoking lasts for $2 \mathrm{~s}$ and is drawn every $30 \mathrm{~s}$ (Hammond et al. 2007). Setting aside the possibility of hose sharing, a closer behavioural model for the narghile user might well be the cigar or the short "dry" pipe smoker.

Certainly, a smoker can draw four puffs per minute over the five first 10 or $15 \mathrm{~min}$, particularly if (s)he has not smoked for 2 or 3 days and also if (s)he is actually observed by a camera or a smoking topography device attached to the pipe. However, beyond this period, and as emphasised, the smoker then does other things than puffing. And before the smoker resumes his/her smoking (for instance after 2 to $5 \mathrm{~min}$, though this figure varies a lot), some reactions (pyrosynthesis for instance) may slow down or not occur, etc. Briefly, such "unexpected" events will a priori have direct consequences on the chemistry of smoke. Another point is that a smoking machine set up with such parameters does not allow the ageing of smoke, which builds up gradually between two puffs above the surface of the water inside the vase and inside the long suction hose ( $1.5 \mathrm{~m}$ on average vs. $0.1 \mathrm{~m}$ for a cigarette). This may be a source of serious artefacts, just like in the case of cigarettes (Borgerding and Klus 2005). Indeed, the underlying mechanisms of tobacco smoke formation are exceedingly complicated (Torikai et al. 2004).

The example of aldehyde generation In view of the huge differences in scale between cigarette and narghile smoking (the duration of a session to start with: approximately 6 min vs. $1 \mathrm{~h}$ ), the modelling bias might be similar in magnitude to the one described by Baker about Fujioka and Shibamoto's experiment in which these authors quantitatively analysed genotoxic carbonyl compounds in cigarette smoke. Their critic noted that the range of yields for four carbonyl compounds (formaldehyde, acetaldehyde, propanal and acrolein) were three to seven times higher than those reported in the classic literature. The reason was that a smoking machine drawing one 20-s continuous puff on the cigarette was used, a fact that was "unrelated to how any human would smoke the cigarette and to how most other researchers have smoked the cigarette over the last 70 years". The risk of a continuous puff would be that the cigarette would burn "unevenly in an irreproducible manner". A natural smoulder period between puffs is necessary (Baker 2006b; Fujioka and Shibamoto 2006).

Average yields of formaldehyde, acetaldehyde, acrolein, propionaldehyde and methacrolein found by Al-Rashidi et al. (2008) with their US-AUB smoking machine were elevated: 630, 2,520, 892, 403 and $106 \mu \mathrm{g}$, respectively, per smoking session. A major source of some of them was sugars. In the case of formaldehyde, Baker (2006a) showed that its yields from the cigarettes containing sugars were significantly higher than those from the control cigarettes at two so-called intense smoking regimes, namely the Canadian and Massachusetts ones. The same scientist also discussed the great contribution of the first puff (in a cigarette) to the generation of formaldehyde. This fact, added to the important question of the relevantly termed "inter-puff smoulder period", are other arguments in favour of a puff-by-puff analysis of narghile smoke (Baker 2006a; Adam et al. 2007; Chaouachi 2007).

Interestingly, in the case of tumbak (plain moistened tobacco), the product traditionally smoked over the past centuries in Asia and Africa, previous studies did not mention high levels of aldehydes in smoke and rather emphasised their water solubility. For instance, French researchers, who early on investigated the compounds playing a role in cilia toxicity, found that they were water soluble and identified two major ones: acrolein and formaldehyde. They speculated that their water solubility could be an explanation for the wide use of the narghile by Middle Eastern populations in spite of the great amounts of tobacco consumed in this device. They relevantly noted that the narghile makes the smoke less irritating (Guillerm et al. 1961). Other researchers found that a very small physiologically wetted surface was capable of complete detoxification of, among other cytotoxins, acrolein and acetaldehyde (Huber et al. 1991).

In the case of jurak, a mixture of $15 \%$ tobacco leaves and $47 \%$ carbohydrates (glucose), an early study was the first to thoroughly identify many of the components of tobacco smoke coming from shishas. The percentage of 
water filtration of organic constituents was found to vary, according to diverse families of compounds, between $78.6 \%$ for phenols and phenolic ethers, and $4.2 \%$ for alkenes and alkynes. The mean total water filtration rate was $38 \%$. Also, it is noteworthy that no polycyclic aromatic hydrocarbons were identified, certainly because the mixture was not heated by charcoal but electrically (El-Aasar and El-Merzabani 1991a). In another study, the same researchers determined by atomic absorption that out of $14.685 \mathrm{mg}$ (heavy) metals present in $1 \mathrm{~g}$ of the jurak paste, only $3.075 \mu \mathrm{g}$ was transferred to the smoker (El-Aasar et al. 1991b).

The stress-strain parameters of Al-Rashidi et al.'s smoking machine may also explain the high yields of formaldehyde for two reasons. On the one hand, in cigarettes, formaldehyde and acrolein reach a maximum yield at $500^{\circ} \mathrm{C}$ (Torikai et al. 2004). However, the temperature of the narghile smoking mixture does not go over $200^{\circ} \mathrm{C}$, whereby the latter is only heated by the charcoal through a thermal pierced-tinfoil screen, as recently pointed out by Sajid et al. (2008). The paste does not release any substantial smoke if it is heated below a temperature of about $300^{\circ} \mathrm{C}$ (unpublished data: Patent 2005). Interestingly, within this range of temperatures, Torikai et al.'s work shows that there is a striking increase of about $150 \mu \mathrm{g} / \mathrm{g}$ of tobacco for the formaldehyde yield and about $300 \mu \mathrm{g} / \mathrm{g}$ of tobacco for that of acrolein (Torikai et al. 2004). It seems that the lower temperature formaldehyde profile is formed essentially by the thermal decomposition of tobacco (Baker 2006a). On the other hand, and in view of both the temperature range and the high proportion of sugars in the narghile smoking mixture, the Maillard reaction [between the aldehyde functions of sugars - especially in the molasses element-and nitrogenous compounds, particularly ammonia $(\mathrm{NH} 4 \mathrm{OH})$, giving birth to various aromatic compounds] appears to be more important than in the case of cigarettes (Chaouachi 2006). A competitive reaction could take place in which sugars give birth either to formaldehyde and/or end products of the Maillard reaction (Baker 2006a). It may be that in Al-Rashidi et al.'s experiment, the Maillard reaction would have been disadvantaged. As for acrolein, one may also wonder, in view of the stress-strain parameters of their smoking machine, whether or not a part of the yield is a result of the cracking of glycerol. Finally, and on a general level, an intense, unrealistic machine smoking regime can make water become quickly saturated and therefore chemically stripped of its natural obstructing properties. An example of this phenomenon was given by Egyptian scientists who showed that water filtration of lead was superior to that of cigarettes (Salem et al. 1990). However, this effect strikingly decreased between one smoking session and the next. Other Egyptian researchers concentrated on this fact and speculated that it could be due to a lack of hygiene as not all smokers change the water after each session (WHO-EMRO 2007).

Alternatives to smoking machines Two alternatives exist. The first one is to avoid using smoking machines. For instance, researchers have noted that for cigarettes it is currently possible to "directly measure cigarette smoke yields experienced by smokers via post-smoking filter tip measurements" (Borgerding and Klus 2005). The other solution would be to work with smoking machines the way sausages are eaten: i.e., using them only for selected sliced periods of time. For instance, a smoke analysis is performed for the first $5 \mathrm{~min}$, then a rest period of $5 \mathrm{~min}$ is allowed, etc., until the end of a session. And, most importantly, the operators do not forget to move around the coal (topping the bowl containing the tobacco-molasses mixture covered by pierced tinfoil) to avoid bias caused by the possible charring of the smoking mixture. The results could then be compiled together with the measurements on a puff-by-puff analysis. Indeed, the chemistry is expected to change minute by minute, as Adam et al. (2007) showed. Also, different puff volumes will be drawn because narghile puffs in real life vary considerably: from a dozen $\mathrm{ml}$ to 11 and sometimes more.

\section{Conclusion}

In spite of the numerous imperfections of the cigarette smoking model, "averaging" the cigarette smoker's behaviour was scientifically accepted among the scientists who early on (4 decades ago) designed the FTC-based smoking machine for the simple reason that a 5-7-min period (the time for a cigarette to be consumed) was viewed as "short" enough to allow for averaging (and considering as periodical) the smoker's behaviour. Of course, it is not, hence the renewed debates over this question. Smoking machine experts have noted that the corresponding FTC/ ISO (cigarette) yields bear little association with biological measures of uptake among human smokers (Hammond et al. 2007). Now, it is surprising that there has not been such a debate over the relevancy of a smoking machine, implying that the simultaneously individual and collective highly complex narghile smoker's behaviour can be "averaged" to one puff relentlessly drawn every $17 \mathrm{~s}$ for 1 full h (Al-Rashidi et al. 2008). Statements implying that such a machine and the corresponding yields of toxicants reflect human smoking with good precision or that such a machine is "standardised" are clearly unscientific. Moreover, the word "machine" is missing in statements like "a single narghile smoking session yields in the mainstream smoke [...]"; "one narghile smoking session is found to release greater amounts", etc. In another place, the 
correspondence of yields and real exposure is amazingly given as taken for granted: "the yields measured in this study are sufficient to induce various diseases depending on the extent of exposure, and on the breathing patterns of the smokers" (Al-Rashidi et al. 2008). Yet, while it would be easy to find cigarette smokers who could accurately mimic the FTC smoking pattern, it will be very much harder to find a narghile smoker capable of mimicking the strain rhythm of the US-AUB's narghile smoking machine. The time is simply too long. Even common sense shows that such a regime implies that about one out of every four smoking puffs is supposed to be a human breath for a whole 1-h session. In these conditions, the machine is far from providing an acceptable picture of this practice in natural environments in spite of its underlying topography. Against the background of a public health epidemic, a recommended research avenue is to focus on biological measurements of human subjects (urinary carcinogens, chemical or biological markers) carried on in a natural environment and coupled with a puff-by-puff smoke analysis (Adam et al. 2007; Sajid et al. 2008).

Conflict of interest The author has no competing interests. He has never received financial or non-financial, direct or indirect, funding neither from pharmaceutical companies (nicotine "replacement" therapies and products) nor from the tobacco industry. For more details, see Chaouachi (2009) in Int. J. Environ. Res. Public Health; 6(2):798-843).

\section{References}

Adam T, Baker RR, Zimmermann R (2007) Characterization of puffby-puff resolved cigarette mainstream smoke by single photon ionization-time-of-flight mass spectrometry and principal component analysis. J Agric Food Chem 55(6):2055-2061

Al Rashidi M, Shihadeh A, Saliba NA (2008) Volatile aldehydes in the mainstream smoke of the narghile waterpipe. Food Chem Toxicol 46(11):3546-3549

Baker RR (2006a) The generation of formaldehyde in cigarettesOverview and recent experiments. Food Chem Toxicol 44:17991822

Baker RR (2006b) Carbonyl compounds in cigarette smoke. Environ Toxicol 21:621-622

Becquemin MH, Bertholon JF, Attoui M, Roy F, Roy M, Dautzenberg B (2008) Tailles particulaires de la fumée de chicha [Particle size in water pipe smoke]. Rev Mal Respir 25(7):839-46

Borgerding M, Klus H (2005) Analysis of complex mixtures-cigarette smoke. Exp Toxicol Pathol 57(Suppl 1):43-73

Chaouachi K (2006) A critique of the WHO's TobReg “Advisory Note" entitled: "Waterpipe tobacco smoking: health effects, research needs and recommended actions by regulators" (2005). Journal of Negative Results in Biomedicine 5:17 http://www. jnrbm.com/content/pdf/1477-5751-5-17.pdf

Chaouachi K (2007) The narghile (hookah, shisha, goza) epidemic and the need for clearing up confusion and solving problems related with model building of social situations. TheScientificWorldJOURNAL: TSW Holistic Health \&Medicine 7:1691-1696
Chaouachi K (2009) Hookah (shisha, narghile) smoking and environmental tobacco smoke (ETS). A critical review of the relevant literature and the public health consequences. Int J Environ Res Public Health 6(2):798-843 http://www.mdpi.com/1660-4601/6/ 2/798/

El-Aasar AM, El-Merzabani MM (1991a) Studies on jurak smoke. I. The organic constituents of jurak smoke. Journal of King Abdulaziz University (Science) 3:169-181

El-Aasar AM, El-Merzabani MM, Ba-Akel H (1991b) Studies on Jurak Smoke: II. The metallic constituents of jurak paste and jurak smoke. Journal of King Abdulaziz University (Science) 3:183-188

Fromme H, Dietrich S, Heitmann D, Dressel H, Diemer J, Schulz T, Jörres RA, Berlin K, Völkel W (2009) Indoor air contamination during a waterpipe (narghile) smoking session. Food Chem Toxicol 2009 [Epub ahead of print] (10.1016/j.fct.2009.04.017)

Fujioka K, Shibamoto T (2006) Determination of toxic carbonyl compounds in cigarette smoke. Environ Toxicol 21(1):47-54

Guillerm R, Badré R, Vignon B (1961) Effet inhibiteurs de la fumée de tabac sur l'activité ciliaire de l'épithélium respiratoire et nature des composants responsables [Inhibitory effects of tobacco smoke on the respiratory epithelium ciliary activity]. Académie Nationale de Médecine:416-423

Hammond D, Wiebel F, Kozlowski LT, Borland R, Cummings KM, O'Connor RJ, McNeill A, Connolly GN, Arnott D, Fong GT (2007) Revising the machine smoking regime for cigarette emissions: implications for tobacco control policy. Tob Control 16:8-14

Helsinki Declaration (2008) Ethical principles for medical research involving human subjects. 1964-2008 General Assemblies (http://www.wma.net/e/policy/b3.htm)

Huber GL, First MW, Grubner O (1991) Marijuana and tobacco smoke gas-phase cytotoxins. Pharmacol Biochem Behav 40:629-636

Monn C, Kindler P, Meile A, Brandli O (2007) Ultrafine particle emissions from waterpipes. Tob Control 16:390-3

Patent (2005) Narghile with simplified ignition. Appl. EP20050291196. Filed 3 June. Published 14 Dec.

Philip Morris USA (1967) FTC to begin cigarette testing [Press Release, Aug 1)] http://www2.philipmorrisusa.com/en/product facts/tar_nicotine/ftc 1967 press release.asp

Rakower J, Fatal B (1962) Study of narghile smoking in relation to cancer of the lung. Br J Cancer 16:1-6

Sajid KM, Chaouachi K, Mahmood R (2008) Hookah smoking and cancer. Carcinoembryonic antigen (CEA) levels in exclusive/ever hookah smokers. Harm Reduct J 24 May;5(19):http://www. harmreductionjournal.com/content/pdf/1477-7517-5-19.pdf

Salem ES, Mesrega SM, Shallouf MA, Nosir MI (1990) Determination of lead levels in cigarette and goza smoking components with a special reference to its blood values in human smokers. The Egyptian Journal of Chest Diseases and Tuberculosis 37(2)

Shihadeh A, Saleh R (2005) Polycyclic aromatic hydrocarbons, carbon monoxide, "tar", and nicotine in the mainstream smoke aerosol of the narghile water pipe. Food Chem Toxicol 43(5):655-661

Torikai K, Yoshida S, Takahashi H (2004) Effects of temperature, atmosphere and $\mathrm{pH}$ on the generation of smoke compounds during tobacco pyrolysis. Food Chem Toxicol 42(9):1409-1417

WHO-EMRO (World Health Organisation - Eastern Mediterranean Regional Office) and ESPRI (Egyptian Smoking Prevention Research Institute) (2007) Shisha hazards profile "Tobacco Use in Shisha-Studies on Water-pipe Smoking in Egypt". Cairo. ISBN: 978-92-9021-569-1. 84 pages. Prepared by senior editors: Mostafa K. Mohamed, Christopher A. Loffredo, Ebenezer Israel et al

Zielinski S (2005) Smoking machine test inadequate and confusing, but no replacement a decade later. J Natl Cancer Inst 97(1):10-11 